\title{
Pharmacokinetics, Safety and Tolerability of Triflusal and its Main Active Metabolite HTB in Healthy Chinese Subjects
}

Authors

Affiliation
M. Wang, Q. Zhang, M. Huang, S. Zong, W. Hua, W. Zhou

Clinical Pharmacology Laboratory, The Second Affiliated Hospital of Soochow University, Suzhou, China
Key words

triflusal

- pharmacokinetics

- antiplatelet activity

- safety

received 06.08.2013

accepted 13.09.2013

\section{Bibliography}

DOI http://dx.doi.org/

10.1055/s-0033-1357180

Published online:

October 8, 2013

Drug Res 2014;

64: 263-268

(c) Georg Thieme Verlag KG

Stuttgart · New York

ISSN 2194-9379

Correspondence

\section{Q. Zhang}

Chief Pharmacist

Clinical Pharmacology Laboratory

The Second Affiliated Hospital

of Soochow University

NO.1055 Sanxiang Road

215004 Suzhou

China

Tel.: +86/512/67783687

Fax: +86/512/67783686

enigmatz@163.com

\section{Abstract}

$\nabla$

Objective: Triflusal presents comparable antiplatelet activity to aspirin while presenting a more favourable safety profile, and is used in the treatment of thrombosis. The study aimed to evaluate the pharmacokinetics and safety of triflusal and its major metabolite 2-(hydroxyl)-4(trifluoromethyl)- benzoic acid (HTB) in healthy Chinese subjects.

Methods: 30 healthy subjects were recruited in this randomized, single-center, and open-label, parallel, single ascending doses (300, 600, $900 \mathrm{mg}$ ) and multiple doses (600 mg, once daily for 7 days) study. Plasma samples were analyzed with a validated liquid chromatography tandem mass spectrometry (LC/MS/MS) method. Safety was assessed by adverse events, ECG, laboratory testing, and vital signs.

Results: Triflusal was safe and well tolerated. After single-dose administration, triflusal was

\section{Introduction \\ $\nabla$}

Triflusal (2-acetoxy-4-trifluoromethyl benzoic acid; CAS 322-79-2) is a new molecule related to salicylic acid which is used in the prevention and treatment of thromboembolic disease [1,2]. Triflusal inhibits cycloxygenase- 1 in platelets, but seems to leave intact the arachidonic acid metabolic pathway in endothelial cells. Trifusal and HTB stimulate the constitutive activity of NO synthase (cNOS) and consequently increase NO production by endothelial cells and leucocytes. Triflusal presents comparable antiplatelet activity to aspirin while presenting a more favourable safety profile [3].

Triflusal is absorbed in the small intestine and its bioavailability ranges from 83 to $100 \%[1,4]$. It binds to plasma proteins almost entirely (99\%) and crosses organic barriers readily. In humans, rapidly absorbed with a mean $\mathrm{T}_{\max }$ of $0.55-0.92 \mathrm{~h}$ and a mean $\mathrm{t}_{1 / 2}$ kel of $0.35-0.65 \mathrm{~h}$, HTB was absorbed with a mean $\mathrm{T}_{\max }$ of $2.35-3.03 \mathrm{~h}$ and a mean $\mathrm{t}_{1 / 2 \text { kel }}$ of $52.5-65.57 \mathrm{~h}$. $\mathrm{C}_{\max }$ and AUC for triflusal and HTB were approximately dose proportional over the $300-900 \mathrm{mg}$ dose range. In the steady state, the accumulation index (R) indicated that the exposure of triflusal increased slightly with repeated dosing, and the exposure of HTB increased obviously. 3 adverse events certainly related to the investigational drugs occurred in the multiple-dose phase.

Conclusion: Following oral dosing under fasting condition, triflusal is promptly absorbed and rapidly depleted from the systemic circulation. HTB is quickly generated from triflusal and slowly eliminated. Triflusal accumulates slightly in the body. HTB plasma concentration builds up progressively toward steady-state.

triflusal is deacetylated in the liver to HTB as the main active metabolite. And unchanged triflusal and HTB are eliminated primarily through the kidneys [5]. Unchanged triflusal, HTB and HTB glycine conjugate have been identified in the urine. Triflusal has 2 major pharmacological effects: in platelets it inhibits activation of thrombogenic mechanisms, while in the nervous system it blocks the main biochemical pathways that lead to cell damage during ischemia [3].

Following oral dosing, triflusal is promptly absorbed and rapidly depleted from the systemic circulation. Its concentration was measurable only up to $4 \mathrm{~h}$ after administration [2]. Main pharmacokinetic parameters of triflusal and HTB in healthy subjects of literature data $[1,6,7]$ are summarized in $\bullet$ Table 1 . The pharmacokinetic profiles of triflusal or HTB do not appear to have clinically significant differences in elderly or 
Table 1 Pharmacokinetics of triflusal and HTB in healthy subjects from literature data.

\begin{tabular}{|c|c|c|c|}
\hline PK parameters ${ }^{\mathrm{a}}$ & $\begin{array}{l}300 \mathrm{mg}[6] \\
(\mathrm{n}=9)\end{array}$ & $\begin{array}{l}600 \mathrm{mg} \text { [7] } \\
(\mathrm{n}=24)\end{array}$ & $\begin{array}{l}900 \mathrm{mg}[1] \\
(\mathrm{n}=8)\end{array}$ \\
\hline \multicolumn{4}{|l|}{ Triflusal } \\
\hline$C_{\max }(\mu \mathrm{g} / \mathrm{mL})$ & - & $14.48 \pm 7.22$ & $11.61 \pm 1.68$ \\
\hline $\mathrm{T}_{\max }(\mathrm{h})$ & - & $0.875(0.25-1.5)^{\mathrm{b}}$ & $0.88 \pm 0.26$ \\
\hline$t_{1 / 2 \text { kel }}(h)$ & $0.64 \pm 0.08$ & $0.76 \pm 0.64$ & $0.53 \pm 0.12$ \\
\hline $\mathrm{AUC}_{0-\mathrm{t}}(\mu \mathrm{g} / \mathrm{mL} \cdot \mathrm{h})$ & $3.0 \pm 0.5$ & $16.22 \pm 7.58$ & - \\
\hline \multicolumn{4}{|l|}{ HTB } \\
\hline$C_{\max }(\mu \mathrm{g} / \mathrm{mL})$ & - & $65.51 \pm 19.44$ & $92.71 \pm 17.14$ \\
\hline $\mathrm{T}_{\max }(\mathrm{h})$ & - & $2(0.75-12)^{b}$ & $4.96 \pm 1.37$ \\
\hline$t_{1 / 2 \text { kel }}(h)$ & $59.7 \pm 11.3$ & $43.13 \pm 6.56$ & $34.29 \pm 5.32$ \\
\hline $\mathrm{AUC}_{0-\mathrm{t}}(\mu \mathrm{g} / \mathrm{mL} \cdot \mathrm{h})$ & $1321 \pm 304$ & $2877.97 \pm 881.24$ & - \\
\hline
\end{tabular}

younger volunteers $[3,8]$. No plasma accumulation of the parent compound was noticed in volunteers $>80$ years old who received triflusal $300 \mathrm{mg} \times 2 /$ day for 13 days [9]. Additionally, the steadystate level of HTB is reached within 8-10 days of treatment $[10,11]$.

At present, no available data on pharmacokinetics of triflusal and HTB in Chinese subjects are reported. The objective of this study was to evaluate the pharmacokinetic profiles of triflusal and HTB after oral single doses $(300,600,900 \mathrm{mg}$ ) and multiple doses (600 mg, once daily for 7 days) of triflusal capsules in healthy Chinese subjects. Moreover, the safety and tolerability of triflusal in Chinese subjects were also assessed.

\section{Subjects and Methods}

$\nabla$

\section{Study approval}

The clinical trial was licensed in State Food and Drug Administration in China with the registration number of 2010L01996. The study was performed at the Second Affiliated Hospital of Soochow University in Suzhou, China. The study was conducted in accordance with the principles of the Declaration of Helsinki [12] and Good Clinical Practice (GCP) in China [13], and the protocol was approved by the Independent Ethics Committee of the hospital with the approval number of 2013 (12). All study participants gave written informed consent before the conduct of the study-related procedures.

\section{Materials and reagents}

Triflusal reference standard (purity of 99.7\%) and HTB reference standard (purity of 99.9\%) were provided by Henan Furen pharmaceutical R \& D Co., Ltd. (Henan, China). Triflusal capsules (300 mg; lot no. 201303012; expiration date, February 2015) were provided by Henan Furentang medicines Co., Ltd. (Henan, China). 6-methoxysalicylic acid (purity of $98.0 \%$ ) used as an internal standard (IS) was purchased from Sigma (St. Louis, MO, USA).

Methanol, acetonitrile and formic acid were of HPLC grade, and purchased from Tedia Company, Inc. (Fairfield, OH, USA). Analytical-grade ammonium acetate was purchased from Nanjing Chemical Reagent Co. Ltd. (Nanjing, China). HPLC grade water was obtained from a Milli-Q water purification system (Millipore Co., Milford, MA, USA) and used throughout the study. The other chemicals and organic solvents were of analytical or HPLC grade and used without further purification.

\section{Study population}

Chinese healthy volunteers, aged $18-40$ years, male and female (nonpregnant and nonlactating), weighing not less than $50 \mathrm{~kg}$, body mass index (BMI) between 19 and $24 \mathrm{~kg} / \mathrm{m}^{2}$, were enrolled. Subjects were all in good health as determined by their past medical history, physical examination, vital signs, standard laboratory parameters (e.g. haematology, blood chemistry and urinalysis), and 12-lead ECG within 2 weeks before the first dosing of the study medication. Female subjects were required to have a negative pregnancy test at screening and to agree on using an effective contraception method during the study period.

The persons are excluded out of the study who are: infected of hepatitis B or C virus or HIV or Syphilis; pregnant or breastfeeding; having a history of or having pulmonary, cardiovascular, neurological, psychiatric, endocrine or coagulation disorders, having renal or hepatic disease or any physical attributes that may influence the trial results; medicated or using drugs of any kind in $\leq 2$ weeks before the study commencement; having a history of or currently abusing of drugs or alcohol; smoking of more than 5 cigarettes per day or equivalent; participating in another drug study or donation of blood in $\leq 90$ days prior to the study.

\section{Study design}

This was a randomized, single-center, open-label study in which 30 healthy subjects of either sex were randomly assigned to group 1, group 2, and group 3 ( 5 females and 5 males in each group). The subjects were hospitalized at 7:00 pm the night before dosing and required to fast overnight $(10 \mathrm{~h})$. Throughout the sequential single-dose and multiple-dose trials, triflusal was administrated in fasting state. After the trial, the subjects were released and visited the clinic for post-test of vital signs, 12-lead ECG, physical examination, and routine laboratory test. If the principal investigator determined that a subject required additional tests, the subject obeyed these orders.

\section{Single dose administration}

The therapeutic dose of triflusal capsule was $300 \mathrm{mg}, 600 \mathrm{mg}$ or $900 \mathrm{mg}$ once daily. On day 1 , subjects of group 1, group 2, and group 3 received a single oral administration of $300 \mathrm{mg}, 600 \mathrm{mg}$, and $900 \mathrm{mg}$ of triflusal capsules, respectively. Study medication was administered at 7:00 am with $250 \mathrm{~mL}$ of water. Water intake was prohibited within the following $2 \mathrm{~h}$ after drug administration and a standard lunch was served $4 \mathrm{~h}$ after dosing. Blood samples ( $4 \mathrm{~mL}$ each) were collected from vein vessels in the antebrachium predose $(0 \mathrm{~h})$ and $10,20,30$ and $45 \mathrm{~min}$, and $1,1.25,1.5,2,2.5,3$, $3.5,4,6,8,12,24,48,72,120$ and $168 \mathrm{~h}$ after dosing. The blood samples were collected into sodium heparin-coated tubes, immediately kept in icebox, and centrifuged. Following centrifugation ( $4000 \mathrm{rpm}, 5 \mathrm{~min}, 4^{\circ} \mathrm{C}$ ), plasma samples were transferred to polyethylene tubes containing an aliquot of $20 \mu \mathrm{L}$ of $3 \mathrm{M}$ hydrochloric acid, immediately vortex-mixed for $10 \mathrm{~s}$. After that, the plasma samples were centrifuged $\left(16000 \mathrm{rpm}, 3 \mathrm{~min}, 4^{\circ} \mathrm{C}\right.$ ), separated and transported into $2 \mathrm{EP}$ tubes. The tubes were then labeled and stored at $-70^{\circ} \mathrm{C}$ until analysis.

\section{Multiple dose administration}

After single-dose phase from day 1-8, subjects of group 2 were assigned to receive $600 \mathrm{mg}$ of triflusal capsules once daily from day 8 to day 14 in fasting state. On days $11,12,13$, and 14 , predose blood samples ( $4 \mathrm{~mL}$ each) were collected prior to the morning dose to evaluate the achievement of 
steady state condition. On day 14 , blood samples were collected predose $(0 \mathrm{~h})$ and at the same time points as in the single-dose study to $168 \mathrm{~h}$ after dosing. All the other experimental conditions were in consistent with those in the single dose phase.

\section{Plasma sample analysis}

A simple, rapid and sensitive LC-MS/MS assay method was developed and validated for the simultaneous quantification of triflusal and HTB in human plasma. The method validation was carried out according to FDA guidance [14]. A $200 \mu \mathrm{L}$ aliquot was mixed with $50 \mu \mathrm{L}$ of the IS solution of $100.1 \mu \mathrm{g} / \mathrm{mL}$. Then $800 \mu \mathrm{L}$ acetonitrile was added. After vortex for $1 \mathrm{~min}$, the sample was centrifuged at $16000 \mathrm{rpm}$ for $10 \mathrm{~min}$ at $4{ }^{\circ} \mathrm{C}$. The supernatant of $100 \mu \mathrm{L}$ was mixed with $1 \mathrm{~mL}$ of water in an auto-injector vial, and $20 \mu \mathrm{L}$ aliquot was injected into the Agilent 1200 Series HPLC system (Agilent Technologies, Palo Alto, CA, USA) for analysis. The chromatographic separation was achieved on an XTerra ${ }^{\circledR} \mathrm{RP}$ 18 column $(150 \times 4.6 \mathrm{~mm}, 5 \mu \mathrm{m}$; Waters Corporation, MA, USA), with an isocratic solvent mixture [methanol-10 $\mathrm{mM}$ ammonium acetate $(0.5 \%$ formic acid contained), $64: 36(\mathrm{v} / \mathrm{v})$ ] at a flow rate of $1.0 \mathrm{~mL} / \mathrm{min}$. Quantification was achieved with MS-MS detection in negative ion mode for both the analytes and the IS using an MDS Sciex API-4000 mass spectrometer (Applied Biosystem Sciex, Ontario, Canada) equipped with a Turboionspray ${ }^{\mathrm{TM}}$ interface at $650^{\circ} \mathrm{C}$. The ion spray voltage was set at $-4500 \mathrm{~V}$. The source parameters, viz. the nebulizer gas, curtain gas, auxillary gas and collision gas, were set at 55, 35, 65 and 8 psi, respectively. The compound parameters, viz. the declustering potential, collision energy, entrance potential and collision exit potential, were $-9,-8,-10$, and $-10 \mathrm{~V}$ for triflusal, $-60,-52$, -10 , and -10 for $\mathrm{HTB}$, and $-40,-16,-10$, and $-16 \mathrm{~V}$ for IS. Detection of the ions was carried out in the multiple-reaction monitoring mode (MRM), by monitoring the transition pairs of $\mathrm{m} / \mathrm{z} 246.9$ precursor ion to the $\mathrm{m} / \mathrm{z} 204.8$ for triflusal, $\mathrm{m} / \mathrm{z} 204.9$ precursor ion to the $\mathrm{m} / \mathrm{z} 160.8$ product ion for $\mathrm{HTB}$, and $\mathrm{m} / \mathrm{z}$ 166.9 precursor ion to the $\mathrm{m} / \mathrm{z} 123.0$ product ion for IS. Quadrupoles Q1 and Q3 were set on unit resolution. The analysis data obtained were processed by Analyst software ${ }^{\mathrm{TM}}$ (version 1.4.2). The calibration curves obtained were linear $\left(r^{2} \geq 0.99\right)$ over the concentration range of $0.03-30 \mu \mathrm{g} / \mathrm{mL}$ for triflusal and $1-200 \mu \mathrm{g} /$ $\mathrm{mL}$ for HTB, respectively. The intra- and inter-batch precisions for the quality control $(\mathrm{QC})$ samples prepared at the low $(0.06 \mu \mathrm{g} /$ $\mathrm{mL}$ and $2 \mu \mathrm{g} / \mathrm{mL}$ for triflusal and HTB, respectively), medium $(1.2 \mu \mathrm{g} / \mathrm{mL}$ and $16 \mu \mathrm{g} / \mathrm{mL}$ for triflusal and HTB, respectively) and high $(24 \mu \mathrm{g} / \mathrm{mL}$ and $160 \mu \mathrm{g} / \mathrm{mL}$ for triflusal and HTB, respectively) concentrations ranged from 2.1 to $6.8 \%$ and 1.8 to $7.5 \%$, respectively. Triflusal and HTB were stable at bench-top stability ( $3 \mathrm{~h}$ ), repeated freeze - thaw cycles ( 3 cycles), and long-term stability at $-70^{\circ} \mathrm{C}$ for 35 days.

\section{Pharmacokinetic analysis}

The pharmacokinetic parameters were estimated using noncompartmental pharmacokinetic methods with WinNonlin Professional software (Version 6.3, Pharsight Corporation, Mountain View, CA, USA). The pharmacokinetic parameters studied in the study included maximum plasma concentration $\left(C_{\max }\right), C_{\max }$ at steady state $\left(C_{s s-\max }\right)$, time to reach $C_{\max }\left(T_{\max }\right)$, minimum plasma concentration at steady state $\left(\mathrm{C}_{\mathrm{ss}-\mathrm{min}}\right)$, average value of the steady-state plasma concentration $\left(C_{a v}\right)$, elimination half-life $\left(t_{1 / 2 \text { kel }}\right)$, area under the plasma concentration-time curve (AUC) from time zero to $t$ post-dosing $\left(\mathrm{AUC}_{0-\mathrm{t}}\right)$, AUC from time zero to infinity $\left(\mathrm{AUC}_{0-\infty}\right)$, elimination rate constant $\left(\mathrm{K}_{\mathrm{el}}\right)$, apparent clear- ance $(\mathrm{CL} / \mathrm{F})$, and the apparent total volume of distribution $(\mathrm{Vd} / \mathrm{F})$, accumulation index (R) and the degree of fluctuation (DF). $C_{\max }$, $\mathrm{T}_{\text {max }}, \mathrm{C}_{\mathrm{ss} \text {-max }}$ and $\mathrm{C}_{\mathrm{ss} \text {-min }}$ were obtained directly from the observed data. Kel was obtained as the slope of the linear regression of the terminal portion of the curve. $t_{1 / 2}$ kel was calculated as $0.693 / \mathrm{Kel}$. $\mathrm{C}_{\mathrm{av}}=\mathrm{AUC}_{\mathrm{sS}} / \tau(\tau=24) . \mathrm{R}_{\mathrm{auc}}=\mathrm{AUC}_{\mathrm{ss}} / \mathrm{AUC}_{0-\mathrm{t}}\left(\mathrm{AUC}_{0-\mathrm{t}}\right.$ was the AUC calculated from zero to $t$ post-dosing in the single dose phase). $\mathrm{R}_{\mathrm{cmax}}=\mathrm{C}_{\mathrm{sS}-\max } / \mathrm{C}_{\max }\left(\mathrm{C}_{\max }\right.$ was the maximum plasma concentration observed in the single dose phase $) . D F=\left(C_{s s-m a x}-C_{s s-m i n}\right) / C_{a v}$.

\section{Statistical analysis}

Statistical analysis was performed using SPSS software (version 17.0, SPSS, Inc, Chicago, Illinois). For the exploration of dose proportionality, the slope $\beta$ and $90 \%$ confidence intervals (CIs) obtained from the power model: $\ln \left(\right.$ AUC or $\left.C_{\text {max }}\right)=\alpha+\beta \times \ln$ (dose) were computed by covariance (ANCOVA) to quantify dose proportionality for triflusal and HTB. The pre-defined criterion $(0.500,2.000)$ is proposed for exploratory dose proportionality assessments across the complete dose range [15]. One-way ANOVA was also used to evaluate any differences in $t_{1 / 2 \mathrm{kel}}, \mathrm{CL} / \mathrm{F}$, and $\mathrm{Vd} / \mathrm{F}$ among the single dose treatments. For $\mathrm{T}_{\max }$, non-parametric test (NPT) was used to evaluate the differences among dose groups. The paired t-test (PTT) was applied to evaluate whether the pharmacokinetic parameters were in concordance with those reported in the single-dose phase. Statistical significance was set at $\mathrm{P}<0.05$ in all the tests.

Summary statistics (number of subjects, means, standard deviations, minimum, maximum, etc.) of the demographic characteristics were calculated for each group.

\section{Safety assessment}

The safety of triflusal was evaluated by monitoring adverse events (AEs), laboratory parameters, vital signs and 12-lead ECG recordings. Vital signs were measured pre- and post-dose. After the trial, heart rate, blood pressure, 12-lead ECG, and body temperature were measured, and clinical examinations and routine laboratory tests were performed.

\section{Results}

\section{$\nabla$}

\section{Study population}

A total of 30 healthy Chinese subjects ( 15 males and 15 females) with age of $18-26$ (mean \pm SD, $23 \pm 2$ years), weight of $50.0-73.0$ (57.0 $\pm 6.4 \mathrm{~kg})$, height of $1.520-1.810(1.650 \pm 0.071 \mathrm{~m})$ and body mass index (BMI) of 19.1-23.8 $\left(20.9 \pm 1.4 \mathrm{~kg} / \mathrm{m}^{2}\right)$ were enrolled in the study after signing the informed consent form. Demographic parameters for subjects are summarized in $\bullet$ Table 2 . No subject halted the study or dropped out.

\section{Pharmacokinetics}

Single dose administration

The mean plasma pharmacokinetic variables for triflusal and HTB after single dose of 300,600, $900 \mathrm{mg}$ of triflusal capsules in fasting state are presented in $\bullet$ Table 3, and the representative plasma concentration-time profiles are shown in $\bullet$ Fig. 1.

Over the 300-900 $\mathrm{mg}$ dose range, $\mathrm{C}_{\max }$ and AUC increased in proportion to the doses for both triflusal $(r=0.890,0.934$, and 0.876 for $\mathrm{C}_{\text {max }}, \mathrm{AUC}_{0-4} \mathrm{~h}$ and $\mathrm{AUC}_{0-\infty}$, respectively) and $\mathrm{HTB}(\mathrm{r}=0.953$, 0.952, and 0.764 for $C_{\max }, A_{U C} C_{0-168 \mathrm{~h}}$ and $\mathrm{AUC}_{0-\infty}$, respectively). For triflusal, the mean slopes ( $90 \% \mathrm{CIs})$ were $1.244(1.040,1.449)$ for $\mathrm{C}_{\max }, 1.043(0.915,1.172)$ for $\mathrm{AUC}_{0-\mathrm{t}}$, and $0.935(0.769,1.101)$ 
for $\mathrm{AUC}_{0-\infty}$. For $\mathrm{HTB}$, The mean slopes (90\% CIs) were 0.900 $(0.807,0.992)$ for $C_{\text {max }}, 0.699(0.561,0.838)$ for $A U C_{0-t}$, and 0.650 $(0.474,0.826)$ for $A_{U C} C_{0-\infty} C_{\max }$ and AUC for triflusal and HTB were approximately dose proportional over the $300-900 \mathrm{mg}$ dose range. $T_{\max }, t_{1 / 2 \text { kel }}, \mathrm{Vd} / \mathrm{F}$ and $\mathrm{CL} / \mathrm{F}$ were independent of dose for triflusal $(P>0.05)$, which indicated kinetic linearity for triflusal. For HTB, significant differences $(P<0.05)$ were found in $t_{1 / 2} \mathrm{kel}$ between dose of 300 and $600 \mathrm{mg}, \mathrm{Vd} / \mathrm{F}$ between dose of 300 and $900 \mathrm{mg}, \mathrm{CL} / \mathrm{F}$ between dose of 300 and $600 \mathrm{mg}$, and CL/F between group dose of 300 and $900 \mathrm{mg}$. No significant differences were found in $\mathrm{T}_{\max }$ for HTB.

\section{Multiple dose administration}

The representative plasma concentration-time profiles after receiving $600 \mathrm{mg}$ triflusal capsules once daily for 7 consecutive days in fasting state are shown in $\bullet$ Fig. 2 . The pharmacokinetic

Table 2 Demographic data of the 30 Chinese subjects.

\begin{tabular}{|llll|}
\hline Characteristics & $\begin{array}{l}\text { Group 1 } \\
(300 \mathbf{m g})\end{array}$ & $\begin{array}{l}\text { Group 2 } \\
(\mathbf{6 0 0} \mathbf{~ m g )}\end{array}$ & $\begin{array}{l}\text { Group 3 } \\
(\mathbf{9 0 0} \mathbf{~ m g})\end{array}$ \\
\hline $\mathrm{n}$ & 10 & 10 & 10 \\
\hline Gender & & & \\
\hline Male & 5 & 5 & 5 \\
\hline Female & 5 & 5 & 5 \\
\hline Age $(\mathrm{y})$ & $23 \pm 2$ & $23 \pm 3$ & $23 \pm 2$ \\
\hline Weight $(\mathrm{kg})$ & $57.6 \pm 7.2$ & $58.5 \pm 6.4$ & $59.2 \pm 6.1$ \\
\hline Height $(\mathrm{m})$ & $1.656 \pm 0.058$ & $1.659 \pm 0.091$ & $1.666 \pm 0.070$ \\
\hline BMI $\left(\mathrm{kg} / \mathrm{m}^{2}\right)$ & $21.0 \pm 1.7$ & $21.2 \pm 1.2$ & $21.3 \pm 1.4$ \\
\hline
\end{tabular}

$\mathrm{BMI}=$ Body mass Index

Data were presented as mean \pm SD parameters of triflusal and HTB after oral multiple-dose administration were summarized in $\odot$ Table 3.

Triflusal disappeared rapidly from the systemic circulation, and most drug concentrations dropped below the limit of detection of the analytical method $4 \mathrm{~h}$ after administration. Trough plasma concentrations of triflusal were zero. No significant differences $(P>0.05)$ in trough plasma concentrations of HTB before the morning dose among repeated administration days 4, 5, 6, and 7 were found, suggesting that steady-state condition was achieved after multiple doses of $600 \mathrm{mg}$ triflusal capsules once daily for 3 days. The $R_{\text {auc }}$ (triflusal $1.5 \pm 0.3$, HTB $2.1 \pm 0.2$ ) and $R_{\text {cmax }}$ (triflusal $1.5 \pm 0.5$, HTB $1.9 \pm 0.3$ ) showed the exposure of triflusal increased slightly with repeated dosing, and the exposure of HTB increased obviously with repeated dosing.

For triflusal, no significant differences $(\mathrm{P}>0.05)$ in pharmacokinetic parameters $\left(t_{1 / 2} \mathrm{kel}, \mathrm{T}_{\max }, \mathrm{Vd} / \mathrm{F}\right)$ and significant differences $(\mathrm{P}<0.05)$ in pharmacokinetic parameters $\left(\mathrm{C}_{\max }, \mathrm{AUC}, \mathrm{CL} / \mathrm{F}\right)$ were observed between single- and multiple-dose phase. For HTB, no significant differences $(P>0.05)$ in pharmacokinetic parameters $\left(\mathrm{t}_{1 / 2 \mathrm{kel}}, \mathrm{T}_{\max }\right)$ and significant differences $(\mathrm{P}<0.05)$ in pharmacokinetic parameters $\left(\mathrm{C}_{\max }, \mathrm{AUC}, \mathrm{CL} / \mathrm{F}, \mathrm{Vd} / \mathrm{F}\right)$ were observed between single- and multiple-dose phase.

\section{Safety}

Safety data were available for all 30 subjects. Good tolerability was observed in all the treatment periods. All adverse events $(\mathrm{n}=3)$ occurred in the multiple-dose phase. All the 3 subjects presented mild gastrointestinal discomfort after several doses administration, and the AEs were certainly related to the investigational drugs. Both effects disappeared spontaneously after several hours. No clinically significant changes in physical

\section{PK parameters}

\section{Triflusal}

$C_{\max }(\mu \mathrm{g} / \mathrm{mL})$

$\mathrm{T}_{\max }(\mathrm{h})$

$\mathrm{t}_{1 / 2 \mathrm{kel}}(\mathrm{h})$

Kel $(1 / h)$

$\mathrm{CL} / \mathrm{F}(\mathrm{L} / \mathrm{h})$

$\mathrm{Vd} / \mathrm{F}(\mathrm{L})$

$\mathrm{AUC}_{0-4 \mathrm{~h}}(\mu \mathrm{g} / \mathrm{mL} \cdot \mathrm{h})$

$\mathrm{AUC}_{0-\infty}(\mu \mathrm{g} / \mathrm{mL} \cdot \mathrm{h})$

$\mathrm{AUC}_{0-4 \mathrm{~h}} / \mathrm{AUC}_{0-\infty}(\%)$

$\mathrm{AUMC}_{0-4 \mathrm{~h}}$

$\mathrm{AUMC}_{0-\infty}$

$\mathrm{MRT}_{0-4 h}(\mathrm{~h})$

$\mathrm{MRT}_{0-\infty}(\mathrm{h})$

HTB

$C_{\max }(\mu \mathrm{g} / \mathrm{mL})$

$\mathrm{T}_{\max }(\mathrm{h})$

$\mathrm{t}_{1 / 2 \mathrm{kel}}(\mathrm{h})$

$\operatorname{Kel}(1 / \mathrm{h})$

$\mathrm{CL} / \mathrm{F}(\mathrm{L} / \mathrm{h})$

$\mathrm{Vd} / \mathrm{F}(\mathrm{L})$

$\mathrm{AUC}_{0-168 \mathrm{~h}}(\mu \mathrm{g} / \mathrm{mL} \cdot \mathrm{h})$

$\mathrm{AUC}_{0-\infty}(\mu \mathrm{g} / \mathrm{mL} \cdot \mathrm{h})$

$\mathrm{AUC}_{0-168 \mathrm{~h}} / \mathrm{AUC}_{0-\infty}(\%)$

AUMC $_{0-168 \mathrm{~h}}$

$\mathrm{AUMC}_{0-\infty}$

$\mathrm{MRT}_{0-168 \mathrm{~h}}$ (h)

$\mathrm{MRT}_{0-\infty}$ (h)

Data were presented as mean $\pm S$

\begin{tabular}{|c|c|c|}
\hline \multicolumn{2}{|l|}{ Single-dose } & \multirow{2}{*}{$\begin{array}{l}\text { Multiple-dose } \\
600 \mathrm{mg}(\mathrm{n}=10)\end{array}$} \\
\hline $600 \mathrm{mg}(n=10)$ & $900 \mathrm{mg}(\mathrm{n}=10)$ & \\
\hline $11.97 \pm 3.92$ & $18.79 \pm 3.70$ & $16.86 \pm 4.92$ \\
\hline $0.92 \pm 1.13$ & $0.55 \pm 0.34$ & $0.53 \pm 0.35$ \\
\hline $0.65 \pm 0.64$ & $0.35 \pm 0.07$ & $0.44 \pm 0.07$ \\
\hline $1.752 \pm 0.899$ & $2.081 \pm 0.406$ & $1.629 \pm 0.242$ \\
\hline $43.04 \pm 9.42$ & $42.84 \pm 8.69$ & $28.44 \pm 4.51$ \\
\hline $38.23 \pm 34.63$ & $21.12 \pm 4.92$ & $17.67 \pm 2.81$ \\
\hline $13.63 \pm 2.40$ & $21.72 \pm 4.36$ & $20.63 \pm 2.69$ \\
\hline $14.55 \pm 3.20$ & $21.79 \pm 4.37$ & $21.55 \pm 3.19$ \\
\hline $95.1 \pm 11.1$ & $99.7 \pm 0.2$ & $96.5 \pm 9.9$ \\
\hline $14.81 \pm 4.48$ & $22.58 \pm 8.40$ & $23.27 \pm 5.35$ \\
\hline $20.55 \pm 18.15$ & $22.86 \pm 8.52$ & $27.72 \pm 17.47$ \\
\hline $1.10 \pm 0.33$ & $1.02 \pm 0.24$ & $1.15 \pm 0.32$ \\
\hline $1.32 \pm 0.79$ & $1.03 \pm 0.25$ & $1.25 \pm 0.59$ \\
\hline $85.35 \pm 13.35$ & $125.4 \pm 15.6$ & $163.1 \pm 13.4$ \\
\hline $2.65 \pm 0.63$ & $2.35 \pm 0.88$ & $2.50 \pm 1.37$ \\
\hline $52.50 \pm 9.61$ & $58.21 \pm 15.96$ & $53.35 \pm 7.1$ \\
\hline $0.014 \pm 0.003$ & $0.013 \pm 0.003$ & $0.013 \pm 0.002$ \\
\hline $0.120 \pm 0.029$ & $0.125 \pm 0.028$ & $0.057 \pm 0.013$ \\
\hline $8.836 \pm 1.390$ & $10.02 \pm 1.42$ & $4.341 \pm 0.665$ \\
\hline $4646 \pm 944$ & $6575 \pm 1388$ & $9663 \pm 1786$ \\
\hline $5252 \pm 1250$ & $7642 \pm 2224$ & $10865 \pm 2212$ \\
\hline $89.2 \pm 4.3$ & $87.4 \pm 6.3$ & $89.3 \pm 2.9$ \\
\hline $248160 \pm 66329$ & $350783 \pm 102578$ & $507336 \pm 121313$ \\
\hline $400021 \pm 158591$ & $638067 \pm 383560$ & $805539 \pm 239205$ \\
\hline $52.80 \pm 4.29$ & $52.75 \pm 4.33$ & $52.02 \pm 3.33$ \\
\hline $73.85 \pm 13.40$ & $78.83 \pm 20.52$ & $72.84 \pm 9.18$ \\
\hline
\end{tabular}

$5.005 \pm 1.736$

$0.85 \pm 0.76$

$0.59 \pm 0.50$

$1.855 \pm 0.993$

$40.87 \pm 11.05$

$29.37 \pm 16.18$

$6.855 \pm 1.308$

$7.987 \pm 2.848$

$90.2 \pm 17.3$

$9.516 \pm 3.441$

$16.391 \pm 16.096$

$1.38 \pm 0.42$

$1.78 \pm 1.05$

$46.59 \pm 6.42$

$3.03 \pm 1.25$

$65.57 \pm 15.12$

$0.011 \pm 0.002$

$0.087 \pm 0.023$

$7.847 \pm 1.068$

$3025 \pm 644$

$3694 \pm 1063$

$83.4 \pm 6.5$

$176383 \pm 49567$

$360666 \pm 190915$

$57.60 \pm 4.69$

$92.64 \pm 21.64$

$73.85 \pm 13.40$
Table 3 Pharmacokinetics of triflusal and HTB after oral single-dose and multiple-dose administration. 


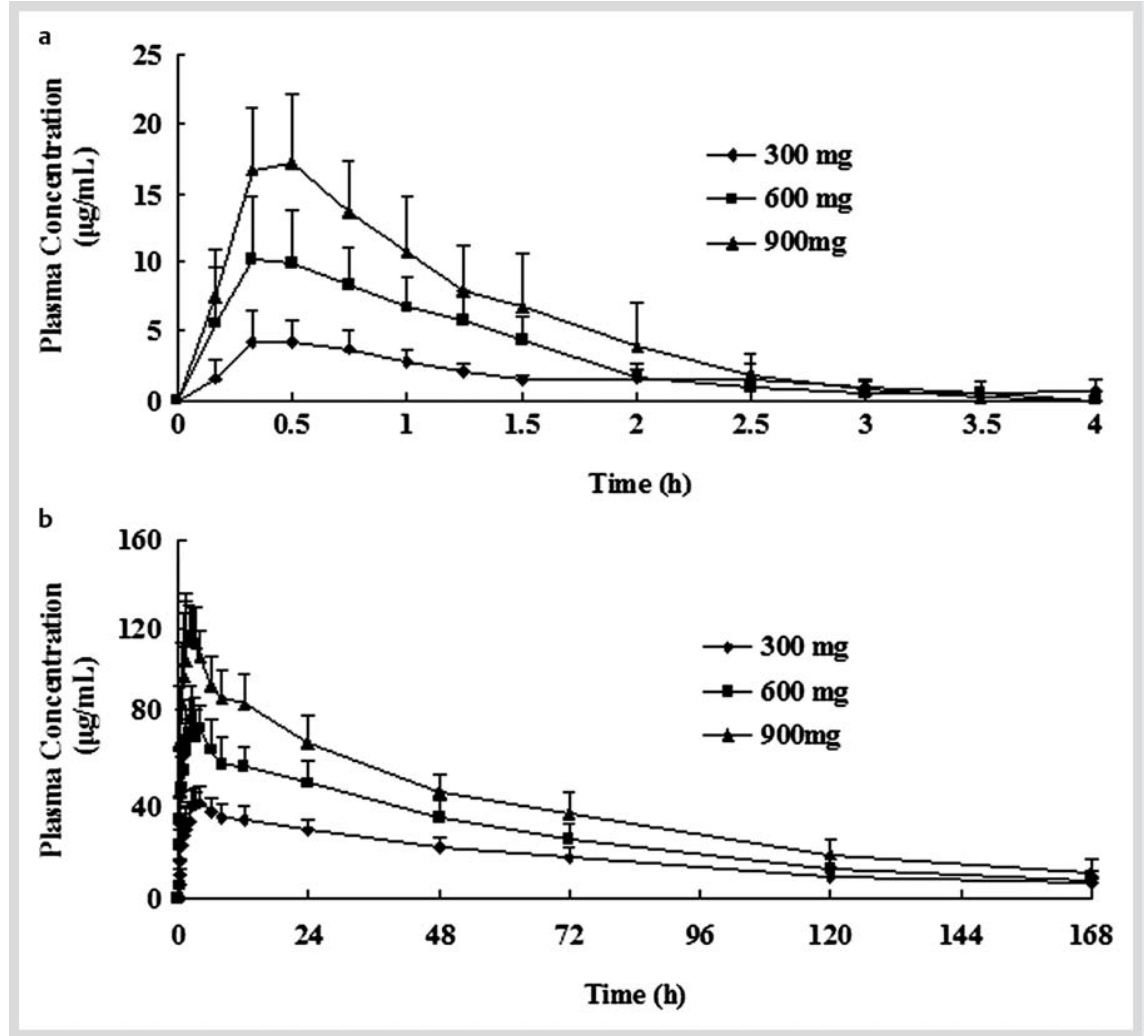

Fig. 1 Plasma concentration-time curves of triflusal $\mathbf{a}$ and HTB $\mathbf{b}$ following single doses of triflusal capsules. Data were presented as mean \pm SD.

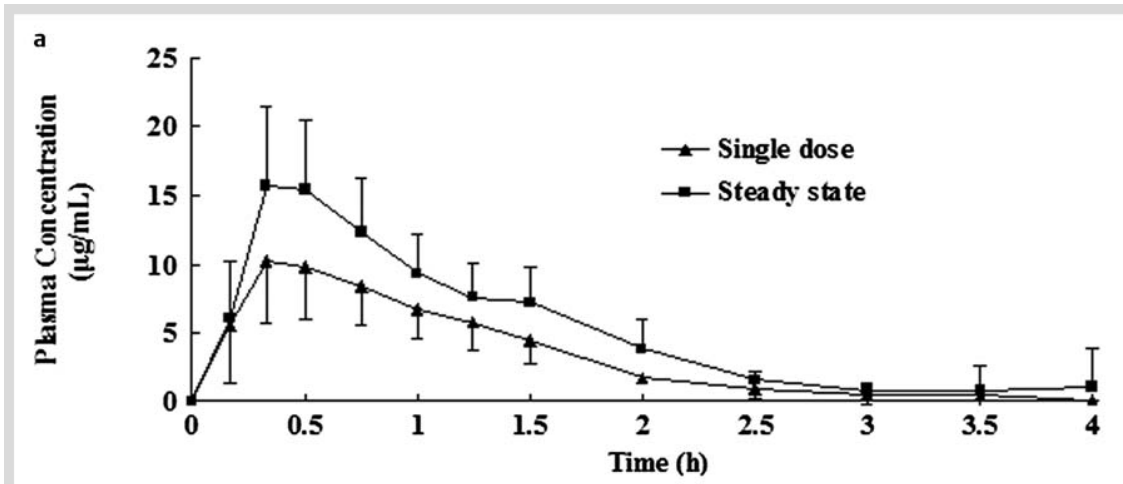

Fig. 2 Plasma concentration-time curves of triflusal $\mathbf{a}$ and HTB $\mathbf{b}$ following a single dose or multiple doses (steady state) of $600 \mathrm{mg}$ triflusal capsules for 7 days. Data were presented as mean \pm SD.

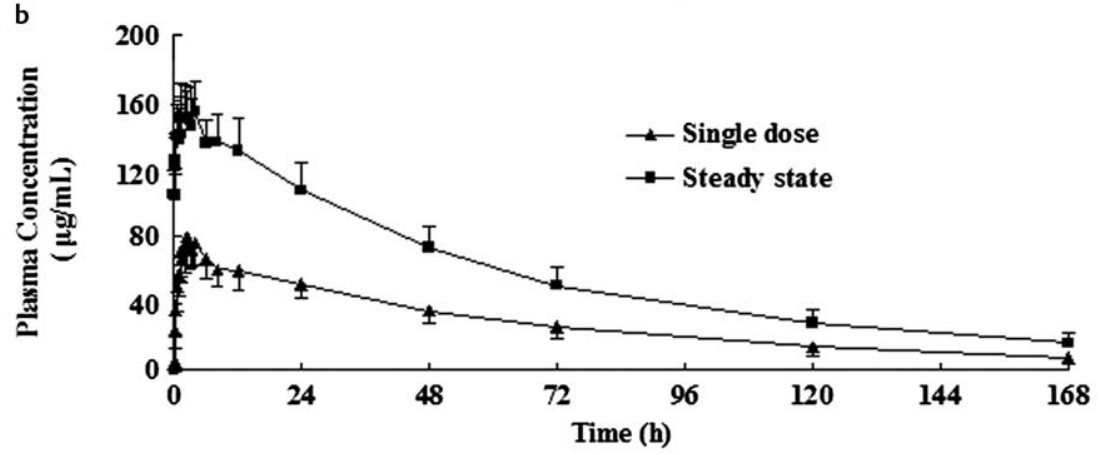

examination, vital signs, 12-lead ECG and safety laboratory testing were observed.

\section{Discussion}

The study evaluated the pharmacokinetic and safety profiles of triflusal and its main metabolite HTB following single doses
$(300,600,900 \mathrm{mg})$ and multiple doses $(600 \mathrm{mg}$, once daily for 7 days) in 30 healthy Chinese subjects.

The results showed that triflusal disappeared rapidly from the systemic circulation, whereas HTB was slowly eliminated. Plasma concentration of triflusal was no longer detectable at $4 \mathrm{~h}$ after oral administration, which was consistent with previous reports about triflusal $[2,16]$. Triflusal did not accumulate in the body, while HTB plasma concentration built up progressively 
towards steady state levels, apparently achieved after 3 days of treatment with the dose regimen proposed.

In the single-dose phase, no adverse event occurred. Over the $300-900 \mathrm{mg}$ dose range, $C_{\max }$ and AUC of triflusal and HTB increased linearly by linear regression analysis. $\mathrm{T}_{\max }$ of triflusal and HTB were dose-independent. The mean $t_{1 / 2}$ kel of triflusal and HTB were similar across all doses. The main pharmacokinetic parameters of triflusal and HTB following single doses (300 mg and $600 \mathrm{mg}$ ) of triflusal capsules are consistent with previous reports $[6,7]$. In the single dose of $900 \mathrm{mg}$ study, the $\mathrm{t}_{1 / 2 \mathrm{kel}}$ of trifusal and HTB were $0.35 \pm 0.07 \mathrm{~h}$ and $58.21 \pm 15.96 \mathrm{~h}$, the $C_{\max }$ of trifusal and HTB were $18.79 \pm 3.70 \mu \mathrm{g} / \mathrm{mL}$ and $125.4 \pm$ $15.6 \mu \mathrm{g} / \mathrm{mL}$, and $\mathrm{T}_{\max }$ of trifusal and HTB were $0.55 \pm 0.34 \mathrm{~h}$ and $2.35 \pm 0.88 \mathrm{~h}$. However, Ramis et al. [1] reported the $t_{1 / 2}$ kel of trifusal and HTB were $0.53 \pm 0.12 \mathrm{~h}$ and $34.29 \pm 5.32 \mathrm{~h}$, the $\mathrm{C}_{\max }$ of trifusal and HTB were $11.6 \pm 1.68 \mu \mathrm{g} / \mathrm{mL}$ and $92.71 \pm 17.14 \mu \mathrm{g} / \mathrm{mL}$, and the $\mathrm{T}_{\max }$ of trifusal and HTB were $0.88 \pm 0.26 \mathrm{~h}$ and $4.96 \pm 1.37 \mathrm{~h}$.

In the multiple-dose phase, 3 subjects presented mild gastrointestinal discomfort after several doses administration, and the adverse events were certainly related to the investigational drugs. Trough plasma concentrations of triflusal were zero. No significant difference in $\mathrm{C}_{\mathrm{ss}-\mathrm{min}}$ of HTB was found by ANOVA analysis. The $T_{\max }$ and $t_{1 / 2}$ kel of trifusal and HTB showed no significant differences between the first and the last dose. The $C_{\max }$ and AUC of trifusal were slightly higher in multiple-dosing administration than the corresponding values obtained after single-dose administration, and slight accumulation was found following repeated dosing ( $R_{c \max } 1.5 \pm 0.5$ and $\left.R_{\text {auc }} 1.5 \pm 0.3\right)$. However, HTB increased obviously with repeated dosing $\left(\mathrm{R}_{\mathrm{cmax}}\right.$ $1.9 \pm 0.3$ and $R_{\text {auc }} 2.1 \pm 0.2$ ). No available data on pharmacokinetics of triflusal following multiple doses are reported. The main pharmacokinetics parameters of HTB following multiple doses (600 mg, once daily for 7 days) of triflusal capsules are consistent with previous reports [17]. However, the $\mathrm{T}_{\max }$ of HTB achieved in previous study [17] were more delayed (median (range), 4 (1-10) h), compared with the findings in our study (median (range), $2(0.75 \sim 4) \mathrm{h}$ ) and other previous reports [10,16].

\section{Conclusions}

$\nabla$

Triflusal capsule was safe and well tolerated in this study. No clinically significant changes in physical examination, vital signs, 12-lead ECG and safety laboratory testing were observed. The most frequently occurring adverse event certainly related to the investigational drugs was gastrointestinal discomfort after multiple doses. The plasma concentration of HTB reached its steady-state condition after multiple doses of $600 \mathrm{mg}$ triflusal capsules once daily for 3 days. The exposure of triflusal increased slightly, and the exposure of HTB increased obviously with repeated dosing.

\section{Acknowledgements}

$\nabla$

The study was sponsored by the Henan Furentang Medicines Co., Ltd., PR China. Quanying Zhang participated in the design of the study protocol, and approved the final protocol. Meng Wang,
Ming Huang, Shunlin Zong, Wenyan Hua, and Wenjia Zhou participated in the collection of data. Quanying Zhang supported the undertaking of the study. All authors participated in the analyses and interpretation of data and writing the manuscript, and approved the final manuscript. The performance of the study, as well as opinions on the analyses, conclusions and the interpretation of the study data, are the responsibility of the authors. The authors take full responsibility for the content of the paper.

\section{Conflict of Interest}

The authors state no conflict of interests in relation to the present study.

\section{References}

1 Ramis J, Mis R, Forn J et al. Pharmacokinetics of triflusal and its main metabolite HTB in healthy subjects following a single oral dose. Eur J Drug Metab Pharmacokinet 1991; 16: 269-273

2 Ferrari E, Reboldi G, Marenco P et al. Pharmacokinetic study of triflusal in elderly subjects after single and repeated oral administration. Am J Ther 1996; 3: 630-636

3 Murdoch D, Plosker GL. Triflusal: a review of its use in cerebral infarction and myocardial infarction, and as thromboprophylaxis in atrial fibrillation. Drugs 2006; 66: 671-692

4 Ramis J, Mis R, Conte L et al. Rat and human plasma protein binding of the main metabolite of triflusal. Eur J Pharmacol 1990; 183: 1867-1868

5 Anninos H, Andrikopoulos G, Pastromas $S$ et al. Triflusal: an old drug in modern antiplatelet therapy. Review of its action, use, safety and effectiveness. Hellenic J Cardiol 2009; 50: 199-207

6 Cho HY, Jeong TJ, Lee YB. Simultaneous determination of triflusal and its major active metabolite, 2-hydroxy-4-trifluoromethyl benzoic acid, in rat and human plasma by high-performance liquid chromatography. J Chromatogr B Analyt Technol Biomed Life Sci 2003; 798: 257-264

7 Quetglas EG, Campanero MA, Sádaba B et al. Bioequivalence of two oral formulations of triflusal capsules in healthy volunteers. Arzneimittelforschung 2008; 58: 283-287

8 McNeely W, Goa KL. Triflusal. Drugs 1998; 55: 823-833

9 Smirne S, Ferini-Strambi L, Cucinotta D et al. II triflusal nella prevenzione degli accidenti cerebrovascolari. G. Gerontol 1995; 43: 563-569

10 Rabasseda X, García-Rafanell J. Triflusal: platelet aggregation inhibition. Drugs Today 1993; 29: 1-34

11 González-Correa JA, De La Cruz JP. Triflusal: an antiplatelet drug with a neuroprotective effect? Cardiovasc Drug Rev 2006; 24: 11-24

12 World Medical Association Declaration of Helsinki. Ethical principles for medical research involving human subjects. http://www.wma.net/en/ 30publications/10polications/10policies/b3/index.html

13 State Food and Drug Administration. Good Clinical Practice Guideline. http://www.sda.gov.cn/WS01/CL0053/24473.html

14 US Department of Health and Human Services, Food and Drug Administration Center for Drug Evaluation and Research (CDER). Guidance for Industry: Bioanalytical Method ValidationMay 2001 http://www.fda. gov/downloads/Drugs/GuidanceComplianceRegulatoryInformation/ Guidances/UCM070107.pdf

15 Hummel J, McKendrick S, Brindley C et al. Exploratory assessment of dose proportionality: review of current approaches and proposal for a practical criterion 2009; $8: 38-49$

16 Ramis J, Torrent J, Mis R et al. Pharmacokinetics of triflusal after single and repeated doses in man. Int J Clin Pharmacol Ther Toxicol 1990; 28: 344-349

17 Lee HW, Lim MS, Seong SJ et al. A phase I study to characterize the multiple-dose pharmacokinetics, pharmacodynamics and safety of new enteric-coated triflusal formulations in healthy male volunteers. Expert Opin Drug Metab Toxicol 2011; 7: 1471-1479 